DOI: $10.11649 /$ abs.2014.009

\author{
Beata Biesiadowska-Magdziarz \\ Instytut Slawistyki PAN \\ Warszawa \\ beata.biesiadowska@wp.pl
}

\title{
Przyczynek do obrazu szlachty Inflant Polskich w łotewskich źródłach i opracowaniach historycznych początku XX w. Perspektywa łotewska
}

Kontakty Łotyszy z Polakami i ich kulturą na przestrzeni dziejów kształtowały się różnie, zarówno w przestrzeni czasowej, jak i terytorialnej. Ogólnie należy stwierdzić, że były niejednakowo głębokie i stabilne w poszczególnych regionach. W Łatgalii i Selonii trwały najdłużej, co jest widoczne do dziś. W Liwlandii i częściowo w Kurlandii, szczególnie w jej środkowej i północnej części - stosunkowo krótko. Dlatego też w sposobie życia tamtejszych mieszkańców, w ich kulturze materialnej i duchowej nie stwierdzono znaczących śladów polskości. W źródłach historycznych znajdujemy zapisy, które z niewielkimi wyjątkami nie sięgają poza drugą połowę XVI w., kiedy to w obawie przed inwazją wojsk cara Iwana Groźnego w 1562 r. ostatni wielki mistrz zakonu krzyżackiego - Gothard Kettler złożył hołd lenny królowi polskiemu Zygmuntowi Augustowi II.

Okres, nazywany w historycznych źródłach łotewskich „polskimi czasami na Łotwie”, trwał w Łatgalii dokładnie 210 lat. Łatgalia od 1561 do 1772 r. (Balodis, 1991, s. 79) początkowo wchodziła w skład Wielkiego Księstwa Litewskiego, a od Unii Lubelskiej (1569) należała do Rzeczpospolitej Obojga Narodów.

Liwlandia pod rządami polskimi znajdowała się krócej - od 1561 do 1629 r., natomiast Księstwo Kurlandii i Semigalii jako księstwo lenne - od 1561 do 1795 r. 
W tym okresie rozpoczęła się również polska migracja na Łotwę. Do tego czasu (to jest do drugiej połowy XVI w.), z wyjątkiem być może jedynie Rygi (która w średniowieczu była jednym z najważniejszych portów bałtyckich), nie spotykano większych zwartych grup polskich. Szczególnie dużo Polaków osiadło na terenach obecnej Łatgalii.

Wśród przybyszów z Polski przeważali przedstawiciele wyższych warstw społecznych (magnatów, szlachty, urzędników sądowych, przedstawicieli władzy administracyjnej, jak również wyższego duchowieństwa). W początkowej fazie przedstawicieli niższych warstw było mało. $Z$ czasem, z powodu częstych wojen i kroczących w ślad za nimi epidemii, m.in. dżumy, dziesiątkujących większą część mieszkańców, szlachta polska z powodów ekonomicznych zmuszona była do sprowadzania chłopów pańszczyźnianych z Polski i z Litwy. Wśród przybyszów byli także spolonizowani Litwini.

Ci Polacy, którzy po przyłączeniu Liwlandii do Szwecji (w 1629 r.) pozostali na miejscu, w kolejnych dwóch-trzech stuleciach zgermanizowali się, część również uległa lettonizacji. Natomiast w Łatgalii i Selonii nastąpił proces odwrotny - niemieckie szlachta i duchowieństwo pod wpływem Polaków w mniejszym lub większym stopniu spolonizowały się. W późniejszym czasie już tylko nazwy majątków i nazwiska rodowe świadczyły o tym, że wielu arystokratów polskich ma korzenie niemieckie, np. Platerowie w Krasławiu (łot. Krāslava), Hylzenowie w Dagdzie (łot. Dagda), Korfowie w Krzyżborgu (łot. Krustpils), Borhowie w Waraklanach (łot. Varakḷāni), Manteufflowie w Drycanach (łot. Dricāni) i in. Polonizacja objęła również pańszczyźnianych chłopów łotewskich. W procesie tym ważną rolę odegrał Kościół katolicki, szczególnie jezuici, którzy od lat 80. XVI w. realizowali twardą politykę kontrreformacyjną.

Niestety brakuje sprawdzonych danych o liczbie, oraz stopniu zagęszczenia Polaków w poszczególnych regionach Łotwy w XVII i XVIII stuleciu. Według źródeł łotewskich pod koniec XIX w. (dokładnie w 1897 r.) Łotwę zamieszkiwało 65056 Polaków, z czego ponad połowa - 30972 - znajdowała się w Łatgalii1. Według danych statystycznych Archiwum Łotwy („Galveno tautîbu piederīgo skaits pēc tautas skaitǐšanu datiem, 1920, 1925, 1930, 1935", b.d.) w 1920 r. na Łotwie mieszkało 54567 (3,4 \% ogółu ludności) Polaków, w 1925 r. - 51143 (2,8 \%), w 1930 - 59374 (3,1 \%), 1935 - 48949 (2,5\%) osób narodowości polskiej. Prawie połowa ludności polskiej zamieszkiwała terytorium Łatgalii (Rozenbergs, 2005, s. 61).

Długotrwała obecność Polaków w tzw. Inflantach Polskich - na obecnym terytorium Łatgalii (polonizacja miejscowej niemieckiej szlachty, a także osadzanie tu polskich chłopów po pokoju oliwskim w 1661 r.), pozostawiła głębokie ślady w narodowej kulturze łotewskiej.

${ }^{1}$ Dane te oczywiście nie są dostatecznie dokładne, gdyż w tamtych czasach za oznakę przynależności narodowej uważano jedynie język. 
W literaturze polskiej, poświęconej roli Polaków w kształtowaniu kultury Łotwy, panuje jednomyślność co do pozytywnych skutków tych wpływów (zob. Kolbuszewski, 1994, ss. 10-23), a opinii badaczy łotewskich w tej kwestii nie poświęca się większej uwagi.

Nie można jednak pomijać milczeniem istnienia diametralnie różnej perspektywy łotewskiej, która szczególnie wyraźnie zarysowała się w pierwszych latach istnienia niepodległego państwa łotewskiego.

Okres silnego oddziaływania Polaków na życie społeczno-kulturalne zyskał negatywną ocenę wielu historiografów Łotwy (np. Francis Kemps, Margérs Skujenieks, Alfrēds Goba, Arveds Švābe i in.). Szczególnej krytyce poddawana była skala oddziaływania kultury polskiej na kulturę rodzimą. Stawiając tę pierwszą w jednym szeregu z destrukcyjnym wpływem kultury rosyjskiej na ogólny rozwój ziem dawnych Inflant Polskich, podkreślano przepaść pomiędzy rozwojem gospodarczo-kulturalnym wschodnich ziem Łotwy, a pozostałą częścią kraju. Zwracano uwagę na fakt, że zbyt długa separacja Łatgalii od pozostałej części Łotwy, zrodziła tam inne warunki życia. Podkreślano zasługi Szwecji dla poprawy położenia chłopów w Inflantach szwedzkich i całkowite zniewolenie chłopów w Inflantach Polskich. W Inflantach Szwedzkich zostały otwarte szkoły ludowe i szkoła wyższa, władze szwedzkie broniły wiary luterańskiej i rozpowszechniały ją. W Łatgalii natomiast szerzyła się polonizacja, a władze polskie popierały katolicyzm, co, zdaniem badaczy łotewskich, nie zostało bez wpływu na rozwój wschodniej części Łotwy.

Porównując Łatgalię z resztą Łotwy, możemy przekonać się o ogromnej różnicy, jaka jest pomiędzy kulturą zachodniej Europy, która pozostawiła na Łotwie swój wpływ, a kulturą rosyjsko-polską. Podczas gdy w Liwlandii i Kurlandii, które od początku, dzięki tamtejszym Niemcom, a w czasach nowszych dzięki trosce samych Łotyszy, utrzymywały silne więzy $\mathrm{z}$ kulturą zachodnią, są ziemie porównywalne z Europą zachodnią, to tymczasem Łatgalia, która przez stosunkowo krótki czas znajdowała się pod półazjatycko-słowiańskim wpływem gospodarczym i kulturowym, jest słabo rozwinięta. Dopiero w ostatnim czasie, dzięki kształtującym się stosunkom pomiędzy Łatgalią a resztą Łotwy, ta różnica w poziomie rozwoju stopniowo wyrównuje się. Jednak miną dziesięciolecia, zanim Łatgalia będzie mogła znaleźć się mniej więcej na tym samym poziomie rozwoju, co Kurlandia i Liwlandia. Poza tym nie ma żadnych wątpliwości, że Łatgalia w wielu aspektach będzie się od reszty Łotwy odróżniać, gdyż nie ma środków, za pomocą których można by było wymazać $\mathrm{z}$ historii Łatgalii 250 -letni osobliwy okres rozwoju (Skujenieks, 1927, s. 185, tłumaczenie własne).

Powodów zacofania gospodarczego tej części kraju upatrywano w ponaddwustuletnim panowaniu Polaków w Łatgalii, z reguły pozytywnie ocenianym przez badaczy polskich².

2 Zob. np. Polacy na Łotwie pod red. Edwarda Walewandra (Walewander, 1993); Kultura polska na Łotwie (1994); G. Manteuffel, Zarysy z dziejów krain dawnych inflanckich, czyli Inflant właściwych (tak szwedzkich jako i polskich), Estonii z Ozylia, Kurlandii i Ziemi Piltyńskiej (Manteuffel, 2007); G. Manteuffel, Inflanty Polskie oraz listy znad Bałtyku (Manteuffel, 2009). 
I tak panowanie Polaków w Łatgalii ciągnęło się [...] ponad 200 lat.

Cały ten długi czas Polacy kontynuowali to swoje dzieło, które nijak nie chciało się powieść w utraconej, zajętej przez Szwedów, części Liwlandii. Tym dziełem historycznym było: ponowne wprowadzenie wiary katolickiej i polonizacja wyższych warstw szlachty. Zachęceni powodzeniem, które odnieśli podczas polonizacji bojarów litewskich i duchowieństwa na Litwie, Polacy byli pełni nadziei, że również w Łatgalii dawne rycerstwo niebawem przyjmie polski język, polską wiarę i polski kontusz [...], a wraz z wyższymi warstwami tłumy ciemnego ludu z łatwością powrócą do starego Kościoła katolickiego. Drogą pochlebstw i przymusu starali się to osiągnąć Polacy. Jeśli to wszystko nie pomagało i niektórzy z nieustępliwości rycerskiej próbowali zostać przy swojej wierze luterańskiej i przy niemieckości, wtedy stosowano wobec nich środki przymusu, jakie tylko Polacy potrafili wymyślić. A „praworządność” polska była giętka jak rózga ich starostów i nadzorców. Nie ufając nawróconej szlachcie niemieckiej, polscy panujący wołali do Łatgalii tłumy polskiej szlachty z Polski i Litwy. Wkrótce obok spolonizowanego możnowładztwa: Platerów, Borchów, Tyzenhauzów, Manteufflów, Romerów, Hylzenów i in. w przestronnych majątkach łatgalskich i miejskich pałacach osiedlili się magnaci polscy: Benisławscy, Szostowiccy, Szadurscy, Skirmunccy, Bujniccy i in.

Gdy w ten sposób możnowładztwo Łatgalii zostało szlachtą polską, wtedy też z przejściem narodu, czyli chłopów łotewskich, na wiarę katolicką nie było żadnych trudności. I prawda, Łatgalczycy, którym zapewne wraz z pozostałą Liwlandią [pozostałymi mieszkańcami Liwlandii] była narzucona reformacja, nie sprzeciwiali się, gdy ich znowu zmieniono w katolików. Przynajmniej historia o tym nic nie opowiada (Kemps, 1910, ss. 8-9, tłumaczenie własne).

Negatywnie oceniano również słabe zainteresowanie szlachty polskiej rozwojem Łatgalii. Wprawdzie wspominano, że wśród autorów licznych opracowań dotyczących Inflant Polskich (świadczy o tym chociażby Bibliografia inflancko-polska Gustawa Manteuffla ${ }^{3}$ ) było najwięcej Polaków, jednakże podkreślano, że w rzeczywistości tworzyła je spolonizowana szlachta niemiecka. Po powstaniu styczniowym w 1863 r., gdy upadły plany uczynienia $z$ Łatgalii prowincji Państwa Polskiego, zainteresowanie pisarzy i badaczy polskich tymi ziemiami znacznie się zmniejszyło. Jedyną znaczącą postacią na tym polu, chociaż również krytykowaną, był wspomniany baron G. Manteuffel. Zarzucano mu m.in. obarczanie całą winą za sytuację w Łatgalii wyłącznie władz rosyjskich oraz jednostronne przedstawianie roli duchowieństwa i szlachty polskiej w rozwoju kulturalno-gospodarczym wschodnich ziem Łotwy.

Historiografia łotewska (m.in. Goba, Kemps) dobitnie podkreślała fakt, że nawet po represjach po powstaniu styczniowym w rękach polskich nadal znajdował się ogromny majątek, a szlachta i duchowieństwo nie utraciło swoich wpływów. Polacy uważali Łatgalię za swoją ziemię i nie byli zainteresowani krzewieniem idei narodo-

${ }^{3}$ G. Manteuffel, Bibliografia inflancko-polska (obejmuje dzieła traktujace o Inflantach polskich a wydane w ciagu ostatnich 5-ciu stuleci, mianowicie od roku 1567 do 1905-go) (Manteuffel, 1906). 
wych wśród miejscowej ludności chłopskiej, która już w niedługim czasie, według możnowładztwa polskiego, miała ulec całkowitej polonizacji:

Na pozór polscy panowie bardzo uprzejmi, mają eleganckie „wychowanie salonowe”, czasami ze współczuciem reagują na ubóstwo i braki wykształcenia prostego ludu i wyrażają gotowość, by cokolwiek zrobić, jeno władza rosyjska im nie pozwala. Niektórym mogłoby się wydawać, że polscy szlachcice są przyjaciółmi Łotyszy. Jednak trzeba by było tylko zajrzeć do ich majątków. Tam język łotewski nawet pomiędzy służbą nie jest tolerowany. Jeśli przyjęty do pracy Łatgalczyk w krótkim czasie nie nauczył się mówić po polsku i nie nauczył się oddawania należytej czci jakoby wyższym istotom, wtedy jego miejsce zajmowała służba przywieziona z Polski, która gięła się podług wszystkich polskich zasad grzeczności. Tak dwór stawał się centrum polonizacji, gdyż Łatgalczyk z całych sił starał się nie utracić miejsca we dworze. Z majątków polonizacja przenikała również do życia wiejskiego, gdzie wspierana była przez księży. W niektórych majątkach ustanowiono tajne szkółki, w których jakiś służący lub specjalnie w tym celu sprowadzony z Polski człowiek uczył dzieci łatgalskie polskiego abecadła i polskich modlitw (Goba, 1933, s. 42, tłumaczenie własne).

Zdaniem badaczy łotewskich, uznanie przez Polaków prawa Łatgalczyków do własnej tożsamości narodowej przyczyniłoby się do rozpoczęcia odrodzenia narodowego w Łatgalii, którego nie byłby w stanie zahamować nawet ucisk władz rosyjskich. Jednakże:

w Łatgalii brutalna rusyfikacja konkurowała z subtelną i zręczną polonizacją. Jeśli już Łatgalczyków jako naród postanowiono wyniszczyć, dlaczegóż więc mieli ich przejąć Rosjanie, a nie Polacy? Podczas gdy Rosjanie starali się [...] przejąć masy chłopskie, Polacy w tym czasie do swojego obozu przeciągnęli śmietankę narodu, tę bardziej zamożną i inteligentną część Łatgalczyków.

We wszystkich majątkach ziemskich Łatgalii, w wielu kościołach katolickich, język polski znajdował się na pierwszym miejscu. Kto chociaż trochę mówił po polsku, ten od Polaków otrzymał wszędzie pomoc i wsparcie, ten wszelako zachęcany był do dalszej nauki polskiego, a także uczenia swoich dzieci tego języka. Najlepsze prace dworskie, najlepsze dworskie folwarki (domy) dawała i dzierżawiła szlachta mówiącym po polsku, czy to byli Polacy, czy Łatgalczycy. We dworach działały nielegalne szkoły polskie, gdzie młodzież polska potajemnie uczyła polskiego dzieci chłopów dworskich, a także dorosłych. W bibliotekach dworskich były [dzieła] wybranych popularnych polskich pisarzy patriotycznych, które rozdawano do czytania w okolicy. Aby zbliżyć się jeszcze bardziej do warstwy chłopskiej, liczni Polacy uczyli się łatgalskiego i chętnie spotykali się z młodzieżą szkół łatgalskich, kilku pilniejszych młodzieńców wspierając nawet materialnie i goszcząc w swoich domach (Kemps, 1938, s. 86, tłumaczenie własne).

Polonizację ludności łatgalskiej uznano za jeden z najbardziej szkodliwych procesów w dziejach odradzającej się Łatgalii, gdyż w ten sposób Łatgalczycy utracili wielu światłych przedstawicieli własnego narodu, którzy polonizując się, odcinali się od własnych łatgalskich korzeni. 
Od początku obecności Polaków na Łotwie rdzenna kultura lokalna stała w opozycji do kultury polskiej.

Ogromny wpływ inflanckiej szlachty polskiej na kulturę, gospodarkę, a także na kreowanie tożsamości narodowej łatgalskich Łotyszy, programowe działania duchowieństwa polskiego oraz polonizacja miejscowej ludności, przyczyniły się do negatywnej oceny wpływów polskich na ziemiach łotewskich.

$\mathrm{W}$ „zasługach” szlachty polskiej dla kultury Łatgalii, podkreślanych przez badaczy polskich, badacze łotewscy upatrywali przyczyn większości nieszczęść tego regionu Łotwy: zacofanie gospodarcze i odrębność kulturową, które stały się szczególnie widoczne w czasie kształtowania się państwowości łotewskiej.

Poglądy większości historiografów łotewskich można podsumować słowami jednego z pisarzy tamtego okresu - Adolfsa Erssa, zdaniem którego „niczego dobrego narodowi łatgalskiemu ta szlachta nie dała, a jakiekolwiek zasługi w rozwoju tego obszaru należą do poszczególnych osób, a nie do szlachty jako ogółu" (Salceviča, 1990, s. 27, tłumaczenie własne), a prace wybitnego arystokraty polskiego niemieckiego pochodzenia Gustawa Manteuffla to ,jedyny pomnik szlachty łatgalskiej. W kulturze łatgalskiej o słynnych rodach szlacheckich niczego więcej znaleźć nie można" (Salceviča, 1990, ss. 27-28, tłumaczenie własne).

Przedstawione opracowanie jest jedynie próbą naszkicowania zagadnienia, któremu dotychczas badacze polscy nie poświęcili większej uwagi, a które to ze względu na bogaty materiał wymaga szczegółowych i szeroko zakrojonych badań. W artykule został zaprezentowany jedynie drobny wycinek obszernego materiału, który posłużył wyłącznie jako ilustracja do przedstawionego szkicu. Głębsza analiza oraz wyczerpujące omówienie znajdzie się w szerszym opracowaniu podjętego tematu.

\section{Bibliografia}

Balodis, A. (1991). Latvijas un latviešu tautas vēsture. Rīga: Neatkarīgā Teātra Kabata Grāmatu Apgāds. Dreimanis, P. (1934). Latvju tautiskā atmoda un valstiskā neatkarība. Jelgava: Latvijas vidusskolu skolotāju kooperātīvs.

Dunsdorfs, E. (1991). Latgales vēsturiskās kartes. Melburnā: Kārḷa Zariņa fonds.

Galveno tautību piederīgo skaits pēc tautas skaitǐ̌anu datiem, 1920, 1925, 1930, 1935. W Latvijas Statistika. Pobrano 5 maja 2014, z http://www.csb.gov.lv/statistikas-temas/iedzivotaji-ticiba-tautiba-uc-tema-32901.html

Goba, A. (1933). Latgale. Latgalieši spaidu laika. Nacionālisma, rakstniecības, biedrošanas un skološanas sākums. Attiecības ar baltiešiem. Rīga: Valters \& Rapa.

Handke, K. (2000). Wizerunek sąsiadów. W R. Bobryk \& J. Faryno (Red.), Polacy w oczach Rosjan - Rosjanie w oczach Polaków: zbiór studiów (ss. 11-14). Warszawa: Slawistyczny Ośrodek Wydawniczy. 
Jēkabsons, Ē. (2007) Piesardzīga draudzība: Latvijas un Polijas attiecības 1919. un 1920. gadā. Rīga: LU Akadēmiskais Apgāds.

Kemps, F. (1910). Latgalieši. Kultur-vesturiska škice. Rīga: Ġeneralkomisijâ pie D. Zeltinạ.

Kemps, F. (1938). Latgales likteñi: ainas no senās un jaunākās pagātnes. Rīga: Eraksti.

Kolbuszewski, J. (1994). Kultura polska na Łotwie. W Kultura polska na Łotwie [Poḷu kultūra Latvijā]. [Wersja polska] (ss. 10-23). Ryga: Ambasada Rzeczypospolitej Polskiej w Rydze.

Kultura polska na Łotwie [Poḷu kultūra Latvijā]. (1994). [Wersja polska]. Ryga: Ambasada Rzeczypospolitej Polskiej w Rydze.

Lācis, V. (2006). Latviešu zemes un tautas vēsture. Rīga: „Vieda”.

Manteuffel, G. (1906). Bibliografia inflancko-polska (obejmuje dzieła traktujace o Inflantach polskich a wydane w ciagu ostatnich 5-ciu stuleci, mianowicie od roku 1567 do 1905-go). Poznań.

Manteuffel, G. (2007). Zarysy z dziejów krain dawnych inflanckich, czyli Inflant właściwych (tak szwedzkich jako i polskich), Estonii z Ozyliq, Kurlandii i Ziemi Piltyńskiej. (K. Zajas, Wstęp, Red. i Oprac.). Kraków: Universitas.

Manteuffel, G. (2009). Inflanty Polskie oraz listy znad Bałtyku. (K. Zajas, Wstęp, Red. i Oprac.). Kraków: Universitas. (Seria Pisma wybrane, G. Manteuffel, T. 1).

Miḳelsons, R. (1937). Latvijas vēstures lasāmā grāmata (T. 1). Rìga: Valters un Rapa.

Rozenbergs, J. (2005). Leksēmas poḷi semantika latviešu tautasdziesmās. W J. Rozenbergs, Tautas un zemes latviešu tautasdziesmās. Rīga: Zinātne.

Salceviča, I. (1990). Adolfs Erss un Latgale. W A. Erss, Muižnieki (ss. 5-38). Rīga: Zinātne.

Skujenieks, M. (1927). Latvija. Zeme un iedzīvotāji. Rīga: A. Gulbja apgādniecība.

Smalkais, E., \& Vējiņš, J. (Red.). (2007). Latvija likteņa gaitās (9000 B. C. - 2007 A. D.). Rīga: Preses Nams.

Švabe, A. (1926). Pagasta vēsture (T. 1: Lìdz krievu laikiem). Rīga: J. Roze.

Walewander, E. (Red.). (1993). Polacy na Lotwie. Lublin: Redakcja Wydawnictw KUL.

\section{Streszczenie}

W literaturze polskiej poświęconej roli Polaków w kształtowaniu kultury Łotwy panuje jednomyślność co do pozytywnej roli i skutków tych wpływów. Nie można jednak pomijać milczeniem istnienia diametralnie różnej perspektywy łotewskiej, która szczególnie wyraźnie zarysowała się w pierwszych latach istnienia niepodległego państwa łotewskiego.

Od początku obecności Polaków na Łotwie kontakty Łotyszy z Polakami i ich kulturą różnie wyglądały w poszczególnych regionach Łotwy. Okres, nazywany w historycznych źródłach łotewskich „polskimi czasami na Łotwie”, najdłużej trwał 
właśnie w Łatgalii (1561-1772), czyli w tzw. Inflantach Polskich. Tam też zauważalny był największy wpływ kultury polskiej na ludową kulturę łotewską.

Okres ten był negatywnie oceniany przez wielu historyków łotewskich. Krytyce poddawana była skala oddziaływania kultury polskiej na rodzimą kulturę łotewską, a także na ogólny rozwój ziem dawnych Inflant Polskich.

Negatywnie było też oceniane udział szlachty polskiej w rozwoju Łatgalii. Uważając te ziemie za swoje, nie była ona zainteresowana krzewieniem idei narodowych wśród miejscowej ludności chłopskiej, która, według możnowładztwa polskiego, już w niedługim czasie miała ulec całkowitej polonizacji.

Ogromny wpływ inflanckiej szlachty polskiej na kulturę, gospodarkę, a także na kreowanie tożsamości narodowej łatgalskich Łotyszy, programowe działania duchowieństwa polskiego oraz polonizacja miejscowej ludności, przyczyniły się do negatywnej oceny wpływów polskich na ziemiach łotewskich.

Przedstawione opracowanie jest próbą naszkicowania zagadnienia, któremu dotychczas badacze polscy nie poświęcili większej uwagi, a które to ze względu na bogaty materiał wymaga szczegółowych i szeroko zakrojonych badań.

Słowa kluczowe: szlachta; Inflanty Polskie; Łotwa; Łatgalia; wpływy kulturowe

\section{A contribution to the image of Polish Livonia nobility in the Latvian historical sources and studies of the early twentieth century. Latvian perspective}

\section{Summary}

Polish literature devoted to the role of the Poles in shaping Latvian culture presents unanimity as far as the positive role and results of this influence are concerned. However diametrically opposite Lat vian perspective particularly clear in the first years of the existence of independent Latvia needs to be highlighted here.

Contacts between the Latvians and Poles and their cultures differed in different parts of Latvia since the beginning of the Polish presence in this country. The period called 'the Polish times in Latvia' in Latvian historical sources lasted the longest in Latgale (1561-1772), i.e. in the so called Polish Livonia. The Polish influence on Latvian folk culture was the strongest there.

This period, especially the scale of the influence of Polish culture on Latvian native culture as well as general development of this region, was strongly criticized by numerous Latvian historians 
The interest of the Polish noblemen in developing Latgale was subjected to criticism, too. Considering these lands as their own the Poles were not interested in propagating national ideas among local village people who, according to the Polish nobles, were to succumb to complete polonisation.

Great influence of the Polish nobility on culture, economy and creating the national identity of the Latgalian Latvians, the policy of the Polish clergy and polonisation of the local people resulted in a negative opinion of the Polish influence in the Latvian lands.

The study is an attempt to outline the issue which Polish researchers have not paid attention to so far. Nevertheless, regarding rich material it needs detailed research on a large scale.

Keywords: nobility; Polish Livonia; Latvia; Latgalia; cultural influences 